Research Article

\title{
An Integrated Fuzzy Best-Worst-TOPSIS Method for Evaluation of Hotel Website and Digital Solutions Provider Firms
}

\author{
Funda Samanlioglu (D), Ayşe Nur Burnaz $\mathbb{D}^{D}$, Berke Diş (D), Mehmet Doğukan Tabaş (D), \\ and Mehmet Adıgüzel
}

Department of Industrial Engineering, Kadir Has University, Cibali, Istanbul 34083, Turkey

Correspondence should be addressed to Funda Samanlioglu; fsamanlioglu@khas.edu.tr

Received 23 July 2020; Accepted 22 October 2020; Published 3 November 2020

Academic Editor: Katsuhiro Honda

Copyright (C) 2020 Funda Samanlioglu et al. This is an open access article distributed under the Creative Commons Attribution License, which permits unrestricted use, distribution, and reproduction in any medium, provided the original work is properly cited.

\begin{abstract}
In today's world where technology is rapidly evolving, hotels need to be the best in all conditions to be one step ahead of other competitors. Digital marketing and hotel website solutions play a lead role in this competition. Therefore, hotel websites need to be innovative, user-friendly, and descriptive. The main purpose of the study is to evaluate and rank potential hotel websites and digital solutions provider firms. Since there are various potentially competing quantitative and qualitative criteria to take into consideration in the decision-making process, a multicriteria decision-making (MCDM) method is needed. As the MCDM method, fuzzy best-worst method (FBWM) is integrated with the Fuzzy Technique for Order Preference by Similarity to Ideal Solution (F-TOPSIS). In this integration, FBWM is applied to determine fuzzy evaluation criteria weights and then F-TOPSIS is implemented to rank alternatives utilizing the obtained fuzzy weights. A case study is presented, where 4 alternative hotel websites and digital solutions provider firms for Paloma Hotels in Turkey are evaluated based on 9 criteria by 3 hotel managers.
\end{abstract}

\section{Introduction}

With the introduction of web technologies at the beginning of the 90s, the Internet has become the most effective communication tool for today. User experience and website quality concepts have come to the fore with the development of web technologies. Utilizing web applications that can work in harmony with the company's business processes is especially significant in the competitive tourism sector. The hotel industry should benefit from the accessibility of the Internet by creating effective digital marketing solutions and websites. Nowadays, hotel customers mostly book online and only the hotels that offer better web platforms to their customers can be superior to their competitors.

There are many website design firms that can design especially hotel websites; however, not all have the potential to provide all or many of the requested features of the websites. For this reason, the purpose of this study is to present a systematic approach for evaluating potential hotel website and digital solutions provider firms with respect to the competing qualitative and quantitative criteria and ranking alternatives from the best to the worst. Due to the nature of the decision-making process, a multicriteria decision-making (MCDM) method is needed and, as the MCDM method, FBWM is integrated with F-TOPSIS in the study. In this integration, FBWM is used to determine fuzzy criteria weights and then F-TOPSIS is applied to rank alternatives utilizing these weights. With Integrated Fuzzy Best-Worst-TOPSIS, both methods' advantages are taken: in FBWM phase, with a few numbers of pairwise criteria comparisons, reliable and consistent fuzzy criteria weights are obtained and then, in F-TOPSIS phase, alternatives are ranked at a reasonable time and effort without complex calculations.

\section{Literature Review}

BWM was developed by Rezai in 2015 [1] and, to illustrate the method, Rezai presented a real-world problem of evaluation and selection of mobile phones. The criteria 
weights obtained with BWM are relatively more reliable than other MCDM methods such as AHP since BWM involves a fewer number of pairwise comparisons that can be bewildering [2]. Due to these advantages, BWM and its fuzzy extension FBWM are implemented in various MCDM problems in the literature. Nawaz et al. [3] implemented BWM to evaluate and rank cloud services. Asadabadi et al. [4] applied BWM to evaluate the specifications of the delivered product and the project provider performance. To also incorporate the imprecision and bluntness in the decision-making process, FBWM has been implemented in various application areas such as evaluation of the severity of pulmonary emphysema [5]; evaluation of transportation modes and supplier performances and selection of a highcost performance car [6]; firefighting helicopters [7], assessment of supplier development [8]; and evaluation of the delivered product and the performance of the provider [4].

TOPSIS, developed by Hwang and Yoon [9] and improved by Hwang et al. [10], emphasizes the idea that the best alternative solution has the shortest distance to positiveideal-solution and largest distance to the negative-idealsolution. To describe the vagueness and ambiguity existent in the decision-making process, its fuzzy extension, F-TOPSIS was developed and implemented in various MCDM problems. Some of these applications are supplier selection in a watch company [11], air carrier evaluation [12], IT personnel selection [13], leaching method selection in hydrometallurgical processes [14], sustainability policy scenario evaluation for the development of electrical vehicles [15], maintenance strategy selection of a cement company [16], green supplier selection [17], evaluation of maintenance strategies for an "off-grid PV-powered street lightening system" [18], and evaluation of energy alternative forms [19].

(Fuzzy) BWM was integrated with several MCDM methods. Ali et al. [20] integrated BWM with a weighted aggregated sum product assessment (WASPAS) method and compared different renewable energy technologies with Solar Home Systems (SHS) in rural regions of Bangladesh. Bai et al. [21] first applied a grey-BWM to determine social sustainability attribute weights, and then a grey-TODIM method to evaluate and rank suppliers. Kumar et al. [22] integrated BWM and VIKOR to evaluate the green performance of the airports. Rahimi et al. [23] applied FBWM to determine criteria weights and fuzzy MULTIMOORA method to evaluate and rank sustainable landfill sites for municipal solid waste. Gul and Ak [24] used FBWM to calculate the relative importance weights of risk factors in the assessment of occupational risks and then fuzzy MAIRCA to rank hazards according to their risk levels utilizing these weights. Ecer and Pamucar [25] implemented FBWM to determine the weights of sustainable supply chain management and then Combined Compromise Solution (CoCoSo) method integrated with Bonferroni functions (CoCoSo'B) to select the best supplier.

(Fuzzy) BWM integrated with (fuzzy) TOPSIS have been used in several applications in the literature. Generally, in this integration, first, the (fuzzy) weights of criteria are determined with (fuzzy) BWM and then the alternatives are ranked with (fuzzy) TOPSIS, using the weights obtained from (fuzzy) BWM. Chang et al. [26] combined BWM and F-TOPSIS based on the concept of aspiration level (fuzzy TOPSIS-AL) to evaluate and rank strategic alliance partners in the green biopharmaceutical Industry. Chang et al. [27] integrated rough BWM with rough TOPSIS to determine the improvement order of failure modes in failure mode and effects analysis. Tian et al. [28] combined BWM with TOPSIS and evaluated green suppliers in the agri-food industry. You et al. [29] implemented a hybrid BWM-TOPSIS approach to rank the operation performance of power grid enterprises in China. Norouzi and Namin [30] first applied FBWM to determine the weights of project success criteria and then implemented F-TOPSIS to prioritize project risk factors for the Tehran-Rasht railway megaproject. Mathiyazhagan et al. [31] combined BWM with F-TOPSIS to first find the weights of material selection criteria and then to rank materials in construction industries. Yucesan et al. [32] integrated BWM with interval type-2 F-TOPSIS to evaluate and rank green suppliers and presented a case study in a plastic injection molding facility in Turkey. Ibrahim et al. [33] used integrated BWM and TOPSIS to evaluate and rank young learners' English mobile applications (E-apps). Gan et al. [34] combined FBWM and modular TOPSIS in random environments for group decision-making (GMoRTOPSIS) to evaluate and select resilient supply chain partners. Serrai et al. [35] applied BWM to normalize the weights associated with the quality of service factors and then implemented VIKOR, SAW, TOPSIS, and COPRAS methods to evaluate web services and used the Borda voting method to determine the compromise solution.

In the literature, website evaluation and web design firm evaluation have been studied in a few papers. Karabasevic et al. [36] implemented Evaluation Based on Distance from Average Solution (EDAS) method to evaluate the websites of the textile industry in Serbia. In their study, they determined criteria weights with Stepwise Weight Assessment Ratio Analysis (SWARA) method. Adalı and Işık [37] applied Organization, Rangement Et Synthese De Donnes Relationnelles (ORESTE) method to rank web design firms for a textile company in Turkey. Büyüközkan and Güleryüz [38] used fuzzy AHP to determine criteria weights and then F-TOPSIS to rank logistics firms' websites. Rouyendegh et al. [39] applied AHP and Intuitionistic Fuzzy TOPSIS to evaluate the performance of e-commerce websites. At present, to the best of the authors' knowledge, integration of FBWM and F-TOPSIS has never been studied, especially for the evaluation of hotel website and digital solutions provider firms. The application steps of the proposed Fuzzy BestWorst-TOPSIS Method is presented in Section 3. In section 4 , a case study in Turkey is given along with conclusions in Section 5.

\section{Fuzzy Best-Worst-TOPSIS Method}

3.1. Definitions. Fuzzy set theory is a mathematical theory of classes with unsharp boundaries [40]. Any crisp theory can be fuzzified by generalizing the concept of a set within that theory to the concept of a fuzzy set [41]. In this paper, due to 
its simplicity, triangular fuzzy numbers (TFNs) are used. A fuzzy number is a special fuzzy set $F=\left\{\left(x, \mu_{F}(x)\right), x \in R\right\}$, where $\mathrm{x}$ is a real number, $R$ : $-\infty<x<+\infty$ and $\mu_{F}(x)$ is a continuous mapping from $R$ to the closed interval $[0,1]$. A TFN denoted as $\widetilde{M}=(l, m, u)$, where $l \leq m \leq u$, has the following triangular type membership function:

$$
\mu_{F}(x)= \begin{cases}0 & x<l, \\ x-l / m-l & l \leq x \leq m, \\ u-x / u-m & m \leq x \leq u, \\ 0 & x>u .\end{cases}
$$

Basic operations between two positive TFNs $\widetilde{A}=\left(l_{1}, m_{1}, u_{1}\right)$ and $\widetilde{B}=\left(l_{2}, m_{2}, u_{2}\right) \quad l_{1} \leq m_{1} \leq u_{1}, l_{2} \leq$ $m_{2} \leq u_{2}$ are explained as

$$
\begin{aligned}
\widetilde{A}+\widetilde{B} & =\left(l_{1}+l_{2}, m_{1}+m_{2}, u_{1}+u_{2}\right), \\
\widetilde{A}-\widetilde{B} & =\left(l_{1}-u_{2}, m_{1}-m_{2}, u_{1}-l_{2}\right), \\
\widetilde{A} * \widetilde{B} & =\left(l_{1} * l_{2}, m_{1} * m_{2}, u_{1} * u_{2}\right), \\
\frac{\widetilde{A}}{\widetilde{B}} & =\left(\frac{l_{1}}{u_{2}}, \frac{m_{1}}{m_{2}}, \frac{u_{1}}{l_{2}}\right), \\
\widetilde{A}^{-1} & =\left(\frac{1}{u_{1}}, \frac{1}{m_{1}}, \frac{1}{l_{1}}\right) .
\end{aligned}
$$

The distance between two positive TFNs can be calculated by the vertex method as [42]

$$
d(\widetilde{A}, t \widetilde{B})=\sqrt{\frac{1}{3}\left(\left(l_{1}-l_{2}\right)^{2}+\left(m_{1}-m_{2}\right)^{2}+\left(u_{1}-u_{2}\right)^{2}\right)} .
$$

Let $\widetilde{C}=\left(l_{3}, m_{3}, u_{3}\right)$ be a triangular fuzzy number. Then, graded mean integration [6] is calculated as

$$
R(\widetilde{C})=\frac{\left(l_{3}+4 m_{3}+u_{3}\right)}{6} .
$$

3.2. Fuzzy Best-Worst Method (FBWM). In the proposed Integrated Fuzzy Best-Worst-TOPSIS method, first, FBWM $[6,30]$ is implemented to determine the fuzzy criteria weights. In FBWM, DMs express their preferences for criteria comparison with the linguistic variables presented in Table 1 and these variables are converted to the corresponding TFNs. [6,30].

The stages of the FBWM are given below.

Step 1. Determine the Evaluation Criteria and DMs. A set of $n\left(C_{1}, C_{2}, \ldots, C_{n}\right)$ (benefit) criteria are determined so that for each criterion maximum is better.

Step 2. Identify the Best and Worst Criteria. Each DM identifies which criterion is best (most desirable) and which is worst (less desirable).
TABLE 1: Linguistic variables and TFNs for the evaluation of criteria.

\begin{tabular}{lc}
\hline Linguistic variables & $\begin{array}{c}\text { Triangular fuzzy } \\
\text { numbers (TFNs) }\end{array}$ \\
\hline Equally preferred (EP) & $(1,1,1)$ \\
Moderately preferred (MP) & $(2 / 3,1,3 / 2)$ \\
Strongly preferred (SP) & $(3 / 2,2,5 / 2)$ \\
Very strongly preferred (VSP) & $(5 / 2,3,7 / 2)$ \\
Extremely more preferred (EMP) & $(7 / 2,4,9 / 2)$ \\
\hline
\end{tabular}

Step 3. Determine the Fuzzy Preference of the Best Criterion Over All Criteria (Best-to-Others (BO) Vector). Each DM determines the preference of his/her best criterion over all other criteria using the linguistic terms in Table 1, which are then converted to TFNs $\left(\tilde{a}_{B j} j=1,2, \ldots, n\right)$. Note that $\widetilde{a}_{B B}=(1,1,1)$.

Step 4. Determine the Fuzzy Preference of All Other Criteria Over the Worst Criterion (Others-to-Worst (OW) Vector). Each DM determines the preference of all other criteria over the worst criterion using the linguistic terms in Table 1, which are then converted to TFNs $\left(\tilde{a}_{j W} j=1,2, \ldots, n\right)$. Note that $\widetilde{a}_{W W}=(1,1,1)$.

Step 5. Calculate the Optimal Fuzzy Weights of the Criteria. For each DM, problem (7) is solved and optimal fuzzy weight vector $\widetilde{W}=\left[\widetilde{w_{1}}, t \widetilde{w_{2}} n, q \ldots h, \widetilde{w_{n}}\right]$ and $\widetilde{\xi}^{*}$ are obtained.

Step 6. Check for consistency.

There are totally $2 n-3$ (n-2 best-to-others fuzzy comparisons $+\mathrm{n}-2$ others-to-worst fuzzy comparisons +1 best-to-worst fuzzy comparison) fuzzy reference comparisons, which need to be executed for FBWM. Note that (fuzzy) BWM only needs $2 \mathrm{n}-3$ comparisons, while (fuzzy) AHP needs $n(n-1) / 2$ comparisons.

In FBWM, optimal fuzzy weights $\widetilde{w}_{j}=\left(l_{j}, m_{j}, u_{j}\right) j=1$, $2, \ldots, n$ can be determined as follows $[6,30]$ :

$$
\begin{aligned}
& \min _{\max _{j}}\left\{\left|\frac{\widetilde{w}_{B}}{\widetilde{w}_{j}}-\tilde{a}_{B j}\right|,\left|\frac{\tilde{w}_{j}}{\widetilde{w}_{W}}-\tilde{a}_{j W}\right|\right\}, \\
& \text { s.t. }\left\{\begin{array}{l}
\sum_{j=1}^{n} R\left(\widetilde{w}_{j}\right)=1, \\
l_{j} \leq m_{j} \leq u_{j}, \quad j=1,2, \ldots, n, \\
l_{j} \geq 0, \quad j=1,2, \ldots, n,
\end{array}\right.
\end{aligned}
$$

where $\quad \tilde{w}_{B}=\left(l_{B}, m_{B}, u_{B}\right) \quad \tilde{w}_{W}=\left(l_{W}, m_{W}, u_{W}\right) \quad \tilde{a}_{B j}=$ $\left(l_{B j}, m_{B j}, u_{B j}\right) \tilde{a}_{j W}=\left(l_{j W}, m_{j W}, u_{j W}\right)$. Problem (5) can be transferred to the following nonlinearly constrained optimization problem: 
$\min \tilde{\xi}$,
s.t. $\left\{\begin{array}{l}\left|\frac{\widetilde{w}_{B}}{\widetilde{w}_{j}}-\widetilde{a}_{B j}\right| \leq \widetilde{\xi}, \quad j=1,2, \ldots, n, \\ \left|\frac{\widetilde{w}_{j}}{\widetilde{w}_{W}}-\widetilde{a}_{j W}\right| \leq \widetilde{\xi}, \quad j=1,2, \ldots, n, \\ \sum_{j=1}^{n} R\left(\widetilde{w}_{j}\right)=1, \\ l_{j} \leq m_{j} \leq u_{j}, \quad j=1,2, \ldots, n, \\ l_{j} \geq 0, \quad j=1,2, \ldots, n,\end{array}\right.$

where $\tilde{\xi}=\left(l^{\xi}, m^{\xi}, u^{\xi}\right)$. Considering $l^{\xi} \leq m^{\xi} \leq u^{\xi}$, suppose $\widetilde{\xi}^{*}=\left(k^{*}, k^{*}, k^{*}\right), k^{*} \leq l^{\xi}$; then problem (6) can be transferred to the following problem:

$\min \tilde{\xi}$

$$
\text { s.t. }\left\{\begin{array}{l}
\left|\frac{\left(l_{B}, m_{B}, u_{B}\right)}{\left(l_{j}, m_{j}, u_{j}\right)}-\left(l_{B j}, m_{B j}, u_{B j}\right)\right| \leq(k *, k *, k *) \quad j=1,2, \ldots, n, \\
\left|\frac{\left(l_{j}, m_{j}, u_{j}\right)}{\left(l_{W}, m_{W}, u_{W}\right)}-\left(l_{j W}, m_{j W}, u_{j W}\right)\right| \leq(k *, k *, k *) \quad j=1,2, \ldots, n, \\
\sum_{j=1}^{n} R\left(\widetilde{w}_{j}\right)=1 \\
l_{j} \leq m_{j} \leq u_{j}, \quad j=1,2, \ldots, n, \\
l_{j} \geq 0, \quad j=1,2, \ldots, n .
\end{array}\right.
$$

By solving the previous problem, optimal fuzzy weights $\widetilde{w}_{j}=\left(l_{j}, m_{j}, u_{j}\right) j=1,2, \ldots, n$ and $\widetilde{\xi}^{*}$ can be obtained.

Checking for consistency [6,30]: the consistency ratio (CR) is used to check the consistency of fuzzy pairwise comparisons. A fuzzy comparison is fully consistent when $\tilde{a}_{B j} \times \tilde{a}_{j W}=\tilde{a}_{B W}$.

By solving equation (8) for different $u_{B W}$ values $\left(\widetilde{a}_{B W}=\left(l_{B W}, m_{B W} u_{B W}\right)\right)$, the maximum possible crisp $\xi$ can be determined and used as a consistency index (CI) for FBWM:

$$
\xi^{2}-\left(1+2 u_{B W}\right) \xi+\left(u_{B W}^{2}-u_{B W}\right)=0 .
$$

CI values calculated for different $\tilde{a}_{B W}$ are listed in Table 2 .
Consistency ratio (CR) is then calculated as follows: CR values closer to zero show high consistency.

$$
\mathrm{CR}=\frac{\xi}{\mathrm{CI}}
$$

3.3. Fuzzy Technique for Order Preference by Similarity to Ideal Solution (F-TOPSIS). In the proposed Integrated Fuzzy Best-Worst-TOPSIS method, after the determination of fuzzy criteria weights with FBWM, F-TOPSIS is applied to rank alternatives from best to worst, utilizing the fuzzy weights obtained from FBWM. In the F-TOPSIS, DMs express their preferences and evaluate alternatives with respect to each criterion using the linguistic variables 
TABle 2: Consistency index (CI) for FBWM.

\begin{tabular}{lccccc}
\hline $\begin{array}{l}\text { Linguistic } \\
\text { variables }\end{array}$ & $\begin{array}{c}\text { Equally preferred } \\
(\mathrm{EP})\end{array}$ & $\begin{array}{c}\text { Moderately preferred } \\
(\mathrm{MP})\end{array}$ & $\begin{array}{c}\text { Strongly preferred } \\
(\mathrm{SP})\end{array}$ & $\begin{array}{c}\text { Very strongly preferred } \\
(\mathrm{VSP}))\end{array}$ & $\begin{array}{c}\text { Extremely more preferred } \\
(\mathrm{EMP})\end{array}$ \\
\hline$\widetilde{a}_{\mathrm{BW}}$ & $(1,1,1)$ & $(2 / 3,1,3 / 2)$ & $(3 / 2,2,5 / 2)$ & $(5 / 2,3,7 / 2)$ & $(7 / 2,4,9 / 2)$ \\
$\mathrm{CI}$ & 3.00 & 3.80 & 5.29 & 6.69 & 8.04 \\
\hline
\end{tabular}

TABLE 3: Linguistic variables and TFNs for the evaluation of alternatives.

\begin{tabular}{lc}
\hline Linguistic variables & Triangular fuzzy numbers (TFNs) \\
\hline Very poor (VP) & $(0,0,1)$ \\
Poor (P) & $(0,1,3)$ \\
Medium poor (MP) & $(1,3,5)$ \\
Fair (F) & $(3,5,7)$ \\
Medium good (MG) & $(5,7,9)$ \\
Good (G) & $(7,9,10)$ \\
Very good (VG) & $(9,10,10)$ \\
\hline
\end{tabular}

presented in Table 3. These variables are then converted to the corresponding TFNs.

Steps of F-TOPSIS $[13,42]$ are presented below. A fuzzy decision matrix with $m$ alternatives and $n$ criteria is given as

$\widetilde{D}=\left[\begin{array}{cccc}\tilde{x}_{11} & \tilde{x}_{12} & \cdots & \tilde{x}_{1 n} \\ \tilde{x}_{21} & \tilde{x}_{22} & \cdots & \tilde{x}_{2 n} \\ \cdot & \cdot & \cdots & \cdot \\ \cdot & \cdot & \cdots & \cdot \\ \tilde{x}_{m 1} & \tilde{x}_{m 2} & \cdots & \tilde{x}_{m n}\end{array}\right]$ where $\tilde{x}_{i j}, \forall i, j$ are linguistic variables that are described by positive TFNs $\tilde{x}_{i j}=\left(a_{i j}, b_{i j}, c_{i j}\right)$ in Table 3. Fuzzy weight vector $\widetilde{W}=\left[\widetilde{w_{1}}, t \widetilde{w_{2}} n, q \ldots h, \underset{w_{n}}{\sim}\right.$ for $n$ criteria was obtained from FBWM.

Step 1. For $l$ DMs, calculate the aggregated $\tilde{x}_{i j}=(1 / l)\left[\tilde{x}_{i j}^{1}+\right.$ $\left.\tilde{x}_{i j}^{2}+\cdots+\tilde{x}_{i j}^{k}+\cdots+\tilde{x}_{i j}^{l}\right]$ where $\tilde{x}_{i j}^{k}$ is the rating of the $k^{t h} \mathrm{DM}$ for the $i^{\text {th }}$ alternative with respect to the $j^{\text {th }}$ criterion.

Step 2. Construct the fuzzy decision matrix $\widetilde{D}$ and normalized fuzzy decision matrix $\widetilde{S}$ for benefit $(B)$ and cost $(C)$ criteria:

$$
\begin{aligned}
\widetilde{S} & =\left[\widetilde{s}_{i j}\right]_{m x n}, \\
\widetilde{s}_{i j} & =\left(\frac{a_{i j}}{c_{j}^{*}}, \frac{b_{i j}}{c_{j}^{*}}, \frac{c_{i j}}{c_{j}^{*}}\right), \quad j \in B, \\
\widetilde{s}_{i j} & =\left(\frac{a_{j}^{-}}{c_{i j}}, \frac{a_{j}^{-}}{b_{i j}}, \frac{a_{j}^{-}}{a_{i j}}\right), \quad j \in C, \\
c_{j}^{*} & =\max _{i} c_{i j}, \quad j \in B, \\
a_{j}^{-} & =\min _{i} a_{i j}, \quad j \in C .
\end{aligned}
$$

Step 3. Construct the weighted normalized fuzzy decision matrix $\widetilde{V}=\left[\widetilde{v}_{i j}\right]_{m x n}$ where $\widetilde{v}_{i j}=\widetilde{s}_{i j} \cdot \widetilde{w}_{j}$ are normalized positive TFNs in the interval $[0,1]$.
Step 4. Define the fuzzy positive-ideal solution $\left(A^{*}\right)$ and fuzzy negative-ideal solution $\left(A^{-}\right), A^{*}=\left(\widetilde{v}_{1}^{*}, \widetilde{v}_{2}^{*}, \ldots, \widetilde{v}_{n}^{*}\right)$, and $A^{-}=\left(\widetilde{v}_{1}^{-}, \widetilde{v}_{2}^{-}, \ldots, \widetilde{v}_{n}^{-}\right)$.

Step 5. Calculate the distance of each alternative from $A^{*}$ and $A^{-}$with the vertex method:

$$
\begin{array}{ll}
d_{i}^{*}=\sum_{j=1}^{n} d\left(\widetilde{v}_{i j}, \widetilde{v}_{j}^{*}\right), & \forall i, \\
d_{i}^{-}=\sum_{j=1}^{n} d\left(\widetilde{v}_{i j}, \widetilde{v}_{j}^{-}\right), \quad \forall i .
\end{array}
$$

Step 6. Calculate the closeness coefficient of each alternative $C C_{i}=d_{i}^{-} / d_{i}^{-}+d_{i}^{*}, \forall i$ and rank the alternatives in decreasing order of closeness coefficient (from the best to the worst) based on $C C_{i}$.

\section{Case Study}

Fuzzy Best-Worst-TOPSIS is applied to evaluate and rank hotel website and digital solutions provider firms for Paloma Hotels in Turkey. In the study, 3 of Paloma Hotels' managers act as DMs. Alternative hotel website and digital solutions provider firms that are evaluated are Travelclick (A1) [43], Sosyalkarinca (A2) [44], Pompaa (A3) [45], and Sarvon (A4) [46]. The evaluation criteria are determined with the help of DMs and listed in Table 4. All the evaluation criteria presented in Table 4 are benefit criteria $(B)$.

First, each DM identifies his/her best and worst criteria and then compares them with other criteria with the linguistic variables presented in Table 1 and these are given in Tables 5 and 6. All the DMs selected criterion C1 as the best criterion and C9 as the worst criterion.

The DMs' linguistic preferences were converted to corresponding TFNs using the scale in Table 1 as seen in Tables 7 and 8 . To determine the fuzzy weights of criteria, problem (7) was solved for each DM and optimal fuzzy criteria weights for each DM and average fuzzy criteria weights were determined, which are given in Table 9. Average fuzzy weights are then used in the F-TOPSIS phase. From equation (8), related consistency indicators $(\xi)$ are determined for each DM as also seen in Table 9. For each DM, $\tilde{a}_{B W}=(7 / 2,4,9 / 2)$, so, as seen from Table 2, CI $=8.04$. From equation (9), DM-1's CR $=0.053$, DM-2's CR $=0.084$, and DM-3's CR $=0.053$. Since all the consistency ratios are close to zero, each DM's criteria comparisons are highly consistent.

In the F-TOPSIS phase, DMs rate each alternative with respect to each criterion using the linguistic variables in Table 3. Evaluations of 4 alternatives with respect to 9 criteria 
TABLE 4: Evaluation criteria for hotel website and digital solutions provider firms.

Efficiency of "content management system" for group hotels (adaptation, accessibility, and efficient management by group hotels):

$\mathrm{C} 1$ "content management system" enables managing the contents of the hotels that have different authorization hierarchy in an efficient way. It enables every hotel web page in the group to be managed by property level managers with appropriate delegation.

$\mathrm{C} 2$

$\mathrm{C} 3$

Live dashboard usability for revenue and reservation management: corporate revenue managers require to follow the reservation flow

C4 with live dashboard to improve sales opportunities. Reservation admins need to follow the reservation flow with live dashboard in order to distribute reservations to hotels and share the guests' preferences with the hotels and follow the payments received in a timely manner. Live dashboard is especially critical for effective timing to make necessary amendments on these processes.

Multiproperty architecture software capability: websites should be designed to include hierarchical architecture in order to be able to C5 assign appropriate rights and authorizations to affiliated departments or hotel properties. Every hotel (department) should be able to manage their content within predefined authorization level for processes such as updating news and changing prices.

C6

C7

$$
\text { Variety of multilingual user interface }
$$

Reporting details and quality

Web technology efficiency for "next generation" (adaptation to future technology): latest web-programming technologies provide C8 critical opportunities for website visitors, such as mobile devices compatibility, dynamic content provided for each individual visitor, and more reliable audio-visual content experience.

Opportunity amount of software as a service-based payment (due to developments on cloud technologies' web-based technology services, instead of perpetual licensing, service-based software purchasing may be used).

TABle 5: Decision-makers' linguistic preferences for the best criterion with regard to each of the other criteria (best-to-others vector).

\begin{tabular}{lccc}
\hline Criteria & DM-1 & DM-2 & DM-3 \\
\hline C1 & EP & EP & EP \\
C2 & MP & EP & EP \\
C3 & MP & MP & MP \\
C4 & SP & SP & SP \\
C5 & VSP & SP & VSP \\
C6 & SP & SP & SP \\
C7 & SP & VSP & SP \\
C8 & VSP & EMP & EMP \\
C9 & EMP & EMP & EMP \\
\hline
\end{tabular}

TABLE 6: Decision-makers' linguistic preferences for all other criteria with regard to the worst criterion (others-to-worst vector).

\begin{tabular}{lccc}
\hline Criteria & DM-1 & DM-2 & DM-3 \\
\hline C1 & EMP & VSP & EMP \\
C2 & EMP & EMP & EMP \\
C3 & VSP & VSP & VSP \\
C4 & SP & VSP & VSP \\
C5 & SP & VSP & MP \\
C6 & VSP & SP & SP \\
C7 & SP & SP & SP \\
C8 & MP & SP & MP \\
C9 & EP & EP & EP \\
\hline
\end{tabular}

TABle 7: Preference of best criterion with regard to each of the other criteria using TFNs (best-to-others vector).

\begin{tabular}{lccr}
\hline Cr. & DM-1 & DM-2 & DM-3 \\
\hline C1 & $(1,1,1)$ & $(1,1,1)$ & $(1,1,1)$ \\
C2 & $(2 / 3,1,3 / 2)$ & $(1,1,1)$ & $(1,1,1)$ \\
C3 & $(2 / 3,1,3 / 2)$ & $(2 / 3,1,3 / 2)$ & $(2 / 3,1,3 / 2)$ \\
C4 & $(3 / 2,2,5 / 2)$ & $(3 / 2,2,5 / 2)$ & $(5 / 2,3,7 / 2)$ \\
C5 & $(5 / 2,3,7 / 2)$ & $(3 / 2,2,5 / 2)$ & $(3 / 2,2,5 / 2)$ \\
C6 & $(3 / 2,2,5 / 2)$ & $(3 / 2,2,5 / 2)$ & $(3 / 2,2,5 / 2)$ \\
C7 & $(3 / 2,2,5 / 2)$ & $(5 / 2,3,7 / 2)$ & $(7 / 2,4,9 / 2)$ \\
C8 & $(5 / 2,3,7 / 2)$ & $(7 / 2,4,9 / 2)$ & $(7 / 2,4,9 / 2)$ \\
C9 & $(7 / 2,4,9 / 2)$ & $(7 / 2,4,9 / 2)$ & \\
\hline
\end{tabular}


TABLE 8: Preference of all other criteria with regard to the worst criterion using TFNs (others-to-worst vector).

\begin{tabular}{lccr}
\hline Cr. & DM-1 & DM-2 & DM-3 \\
\hline C1 & $(7 / 2,4,9 / 2)$ & $(5 / 2,3,7 / 2)$ & $(7 / 2,4,9 / 2)$ \\
C2 & $(7 / 2,4,9 / 2)$ & $(7 / 2,4,9 / 2)$ & $(7 / 2,4,9 / 2)$ \\
C3 & $(5 / 2,3,7 / 2)$ & $(5 / 2,3,7 / 2)$ & $(5 / 2,3,7 / 2)$ \\
C4 & $(3 / 2,2,5 / 2)$ & $(5 / 2,3,7 / 2)$ & $(5 / 2,3,7 / 2)$ \\
C5 & $(3 / 2,2,5 / 2)$ & $(5 / 2,3,7 / 2)$ & $(2 / 3,1,3 / 2)$ \\
C6 & $(5 / 2,3,7 / 2)$ & $(3 / 2,2,5 / 2)$ & $(3 / 2,2,5 / 2)$ \\
C7 & $(3 / 2,2,5 / 2)$ & $(3 / 2,2,5 / 2)$ & $(3 / 2,2,5 / 2)$ \\
C8 & $(2 / 3,1,3 / 2)$ & $(3 / 2,2,5 / 2)$ & $(2 / 3,1,3 / 2)$ \\
C9 & $(1,1,1)$ & $(1,1,1)$ & $(1,1,1)$ \\
\hline
\end{tabular}

Table 9: Fuzzy weights of 9 criteria and related consistency indicator $(\xi)$ for each decision-maker and average fuzzy weights.

\begin{tabular}{lcccr}
\hline Cr. & DM-1 & DM-2 & DM-3 & Fuzzy weights $\widetilde{W}$ (average) \\
\hline C1 & $(0.169,0.185,0.185)$ & $(0.137,0.137,0.137)$ & $(0.176,0.206,0.206)$ & $(0.161,0.176,0.176)$ \\
C2 & $(0.169,0.190,0.193)$ & $(0.230,0.230,0.230)$ & $(0.147,0.206,0.206)$ & $(0.182,0.209,0.210)$ \\
C3 & $(0.100,0.147,0.154)$ & $(0.106,0.137,0.171)$ & $(0.107,0.160,0.160)$ & $(0.104,0.148,0.162)$ \\
C4 & $(0.065,0.104,0.115)$ & $(0.101,0.114,0.126)$ & $(0.099,0.131,0.147)$ & $(0.088,0.117,0.129)$ \\
C5 & $(0.047,0.072,0.081)$ & $(0.101,0.114,0.126)$ & $(0.052,0.060,0.060)$ & $(0.067,0.082,0.089)$ \\
C6 & $(0.089,0.117,0.154)$ & $(0.072,0.086,0.106)$ & $(0.070,0.085,0.099)$ & $(0.077,0.096,0.120)$ \\
C7 & $(0.063,0.104,0.115)$ & $(0.055,0.065,0.081)$ & $(0.070,0.085,0.099)$ & $(0.063,0.085,0.098)$ \\
C8 & $(0.047,0.061,0.076)$ & $(0.046,0.653,0.081)$ & $(0.042,0.047,0.051)$ & $(0.045,0.254,0.069)$ \\
C9 & $(0.039,0.043,0.043)$ & $(0.044,0.049,0.055)$ & $(0.048,0.048,0.048)$ & $(0.044,0.047,0.049)$ \\
$\xi$ & $(0.426,0.426,0.426)$ & $(0.672,0.672,0.672)$ & $(0.426,0.426,0.426)$ & $(0.508,0.508,0.508)$ \\
\hline
\end{tabular}

TABle 10: 3 DMs' evaluations of the hotel website and digital solutions provider firms with respect to each criterion.

\begin{tabular}{|c|c|c|c|c|c|c|c|c|c|}
\hline & $\mathrm{C} 1$ & $\mathrm{C} 2$ & C3 & $\mathrm{C} 4$ & C5 & C6 & C7 & C8 & C9 \\
\hline \multirow{3}{*}{ A1 } & VG & VG & $\mathrm{G}$ & VG & VG & MP & $\mathrm{MG}$ & $\mathrm{G}$ & $G$ \\
\hline & VG & VG & MG & VG & VG & MP & $\mathrm{MG}$ & $\mathrm{G}$ & $\mathrm{MG}$ \\
\hline & VG & VG & $\mathrm{F}$ & VG & VG & MP & $\mathrm{MG}$ & $\mathrm{G}$ & MG \\
\hline \multirow{3}{*}{$\mathrm{A} 2$} & $G$ & $G$ & VG & $G$ & VG & $G$ & $G$ & VG & MP \\
\hline & VG & G & VG & $\mathrm{MG}$ & MG & VG & $\mathrm{G}$ & VG & MP \\
\hline & VG & VG & VG & $\mathrm{G}$ & G & VG & MG & VG & MP \\
\hline \multirow{3}{*}{ A3 } & $\mathrm{G}$ & $G$ & VG & $G$ & $G$ & $G$ & VG & $G$ & MP \\
\hline & G & G & VG & MG & MG & G & VG & $\mathrm{G}$ & MP \\
\hline & VG & VG & VG & $\mathrm{G}$ & G & $\mathrm{G}$ & VG & G & MP \\
\hline \multirow{3}{*}{ A4 } & $F$ & $\mathrm{~F}$ & G & $\mathrm{F}$ & $G$ & $G$ & $\mathrm{G}$ & MG & MP \\
\hline & G & $\mathrm{F}$ & $\mathrm{G}$ & MP & MP & MG & G & $\mathrm{G}$ & MP \\
\hline & MG & MG & G & MG & MG & $\mathrm{F}$ & $\mathrm{G}$ & G & MP \\
\hline
\end{tabular}

Table 11: Fuzzy decision matrix $\widetilde{D}$.

\begin{tabular}{|c|c|c|c|c|c|c|c|c|c|}
\hline & $\mathrm{C} 1$ & C2 & C3 & $\mathrm{C} 4$ & C5 & C6 & C7 & C8 & C9 \\
\hline $\mathrm{A} 1$ & $\begin{array}{r}.000,1 \\
10.0\end{array}$ & 3330 & $\begin{array}{r}(7.667 \\
10 .\end{array}$ & $\begin{array}{r}5.000 \\
8.66\end{array}$ & 000 & 33 & & 667 & $\begin{array}{l}.000 \text {, } \\
\text { ) }\end{array}$ \\
\hline A2 & $\begin{array}{r}(8.33 \\
1\end{array}$ & $\begin{array}{r}(7.66 \\
1\end{array}$ & $\begin{array}{r}(5.00 \\
8\end{array}$ & $\begin{array}{r}(9.000 \\
10\end{array}$ & 33 & 33 & 567, & 000 & .000 \\
\hline A3 & $\begin{array}{c}(7.667,9.333 \\
10.000)\end{array}$ & $\begin{array}{c}(5.000,7.000 \\
8.667)\end{array}$ & $\begin{array}{r}(9.000,1 \\
10.00\end{array}$ & $\begin{array}{r}(7.667,9 \\
10.00\end{array}$ & $\begin{array}{r}(7.667,9 \\
10.00\end{array}$ & $\begin{array}{r}(3.667, \\
7.66\end{array}$ & $\begin{array}{c}(5.000,7.000 \\
8.667)\end{array}$ & $\begin{array}{r}(9.000 \\
10 .\end{array}$ & $\begin{array}{r}(9.000 \\
10\end{array}$ \\
\hline A4 & $\begin{array}{c}(5.000,7.000 \\
8.667)\end{array}$ & $\begin{array}{c}(9.000,10.000 \\
10.000)\end{array}$ & $\begin{array}{c}(7.667,9.333 \\
10.000)\end{array}$ & $\begin{array}{c}(7.667,9.333 \\
10.000)\end{array}$ & $\begin{array}{c}(3.667,5.667, \\
7.667)\end{array}$ & $\begin{array}{c}(5.000,7.000 \\
8.667)\end{array}$ & $\begin{array}{c}(9.000,10.000 \\
10.000)\end{array}$ & $\begin{array}{c}(9.000,10.000 \\
10.000)\end{array}$ & $\begin{array}{c}(7.000,9.000 \\
10.000)\end{array}$ \\
\hline
\end{tabular}

by 3 DMs with the linguistic terms are given in Table 10. Linguistic terms are converted to corresponding TFNs and the aggregated (average) fuzzy decision matrix $(\widetilde{D})$ is presented in Table 11. After the construction of the fuzzy normalized decision matrix $(\widetilde{S})$, the fuzzy weighted normalized decision matrix $(\widetilde{V})$ is determined as seen in Table 12 .
Assuming $A^{*}=((1,1,1), t(1,1,1) n, q(1,1,1) h$, $(1,1,1) x, 7(1,1,1) C, ; \quad(1,1,1),(1,1,1),(1,1,1), \quad(1,1,1))$ and $\quad A^{-}=((0,0,0), t \quad(0,0,0) n, q(0,0,0) h, \quad(0,0,0) x, 7$ $(0,0,0) C ;(0,0,0),(0,0,0), \quad(0,0,0),(0,0,0))$, distance from fuzzy positive-ideal solution $\left(d_{i}^{*}\right)$, distance from fuzzy negative-ideal solution $\left(d_{i}^{-}\right)$, and closeness coefficients $\left(C C_{i}\right)$ are calculated as shown in Table 13 . Based on the $C C_{i}$ values, 
TABLE 12: Weighted normalized fuzzy decision matrix $\widetilde{V}$.

\begin{tabular}{cccccccccc}
\hline & $\mathrm{C} 1$ & $\mathrm{C} 2$ & $\mathrm{C} 3$ & $\mathrm{C} 4$ & $\mathrm{C} 5$ & $\mathrm{C} 6$ & $\mathrm{C} 7$ & $\mathrm{C} 8$ & $\mathrm{C} 9$ \\
\hline \multirow{2}{*}{$\mathrm{A} 1$} & $(0.145,0.176$, & $(0.152,0.202$, & $(0.080,0.138$, & $(0.044,0.082$, & $(0.060,0.082$, & $(0.059,0.090$, & $(0.048,0.079$, & $(0.016,0.144$, & $(0.022,0.033$, \\
& $0.176)$ & $0.210)$ & $0.162)$ & $0.112)$ & $0.089)$ & $0.120)$ & $0.098)$ & $0.053)$ & $0.042)$ \\
& $(0.134,0.170$, & $(0.139,0.195$, & $(0.052,0.104$, & $(0.079,0.117$, & $(0.051,0.077$, & $(0.059,0.090$, & $(0.023,0.048$, & $(0.022,0.178$, & $(0.039,0.047$, \\
A2 & $0.176)$ & $0.210)$ & $0.140)$ & $0.129)$ & $0.089)$ & $0.120)$ & $0.075)$ & $0.060)$ & $0.049)$ \\
& $(0.123,0.164$, & $(0.091,0.146$, & $(0.094,0.148$, & $(0.068,0.109$, & $(0.051,0.077$, & $(0.028,0.054$, & $(0.031,0.059$, & $(0.040,0.254$, & $(0.039,0.047$, \\
A3 & $0.176)$ & $0.182)$ & $0.162)$ & $0.129)$ & $0.089)$ & $0.092)$ & $0.085)$ & $0.069)$ & $0.049)$ \\
& $(0.080,0.123$, & $(0.164,0.209$, & $(0.080,0.138$, & $(0.068,0.109$, & $(0.024,0.047$, & $(0.039,0.067$, & $(0.057,0.085$, & $(0.040,0.254$, & $(0.031,0.042$, \\
A4 & $0.153)$ & $0.210)$ & $0.162)$ & $0.129)$ & $0.068)$ & $0.104)$ & $0.098)$ & $0.069)$ & $0.049)$ \\
& & & & & & & $0.04)$ & &
\end{tabular}

TABLe 13: Weighted normalized fuzzy decision matrix $\widetilde{V}$.

\begin{tabular}{lcccc}
\hline Alternative & $d_{i}^{-}$ & $d_{i}^{*}$ & $C C_{i}$ & Rankings \\
\hline A1 (Travelclick) & 0.9421 & 8.0995 & 0.1042 & 2 \\
A2 (Sosyalkarınca) & 0.9347 & 8.1142 & 0.1033 & 4 \\
A3 (Pompaa) & 0.9425 & 8.1220 & 0.1040 & 3 \\
A4 (Sarvon) & 0.9549 & 8.1086 & 0.1054 & 1 \\
\hline
\end{tabular}

alternatives are ranked from the best to the worst as follows: Sarvon (A4), Travelclick (A1), Pompaa (A3), and Sosyalkarinca (A4).

\section{Conclusions}

Web technologies have become the most effective means of communication in the world with the widespread use of the Internet and this also plays a decisive role in the hotel industry since most customers book hotel rooms or get information about the hotels online. Effective digital marketing and website solutions are of utmost importance for hotels. Evaluating and selecting the best hotel website and digital solutions provider, taking into consideration various potentially conflicting qualitative and quantitative criteria is a MCDM problem by nature.

In this paper, an efficient fuzzy MCDM method, Fuzzy Best-Worst-TOPSIS, is implemented to evaluate and rank hotel website and digital solutions provider firms for Paloma Hotels in Turkey. The integration of FBWM and F-TOPSIS provides the potential practitioners and readers both methods' advantages. In FBWM, the number of pairwise criteria comparisons is less then frequently used F-AHP, and with FBWM, consistent and reliable criteria weights are obtained. Ranking alternatives with F-TOPSIS take a reasonable time and effort with straightforward calculations.

As a result of the implemented Fuzzy Best-WorstTOPSIS method, taking into consideration nine potentially competing evaluation criteria and Paloma Hotels managers' preferences, alternative hotel website and digital solutions provider firms for Paloma Hotels are ranked from the best to the worst as Sarvon, Travelclick, Pompaa, and Sosyalkarınca. At the end of the study, all the assessments and results are shared with Paloma Hotels and Sarvon are suggested as the best alternative.

For future research, the Fuzzy Best-Worst-TOPSIS method can be applied to other MCDM evaluation and ranking problems, especially to problems where there are a large number of criteria and alternatives. Also, in BWM and FBWM comparisons, correlations between criteria are not taken into consideration; hence, these methods may further be improved by introducing the concept of correlation between criteria. Moreover, to reflect the uncertainty, ambiguity, and hesitations DMs might have in their preferences, hesitant fuzzy linguistic term sets and hesitant fuzzy set concepts can be utilized in both BWM and TOPSIS and hesitant fuzzy Best-Worst-TOPSIS method can be implemented to various MCDM problems.

\section{Data Availability}

All the data are included in the manuscript.

\section{Conflicts of Interest}

The authors declare that they have no conflicts of interest.

\section{Acknowledgments}

The authors would like to thank Paloma Hotels' managers Timuçin Diş, Ozan Yılmaz, and Sevilay Aydın for their participation as decision-makers in the process.

\section{References}

[1] J. Rezaei, Best-Worst Multi-Criteria Decision-Making Method, Omega, London, UK, 2015.

[2] J. Rezaei, "Best-worst multi-criteria decision-making method," Omega, vol. 53, pp. 49-57, 2015.

[3] F. Nawaz, M. R. Asadabadi, N. K. Janjua, O. K. Hussain, E. Chang, and M. Saberi, "An MCDM method for cloud service selection using a Markov chain and the best-worst method," Knowledge-Based Systems, vol. 159, pp. 120-131, 2018.

[4] M. R. Asadabadi, E. Chang, O. Zwikael, M. Saberi, and K. Sharpe, "Hidden fuzzy information: requirement specification and measurement of project provider performance using the best worst method," Fuzzy Sets and Systems, vol. 383, pp. 127-145, 2020.

[5] Q. Mou, Z. Xu, and H. Liao, "An intuitionistic fuzzy multiplicative best-worst method for multi-criteria group decision making," Information Sciences, vol. 374, pp. 224-239, 2016.

[6] S. Guo and H. Zhao, "Fuzzy best-worst multi-criteria decision-making method and its applications," Knowledge-Based Systems, vol. 121, pp. 23-31, 2017.

[7] D. Pamučar, I. Petrović, and G. Ćirović, "Modification of the Best-Worst and MABAC methods: a novel approach based on interval-valued fuzzy-rough numbers," Expert Systems with Applications, vol. 91, pp. 89-106, 2018. 
[8] H. Aboutorab, M. Saberi, M. R. Asadabadi, O. Hussain, and E. Chang, "ZBWM: the Z-number extension of Best Worst Method and its application for supplier development," Expert Systems with Applications, vol. 107, pp. 115-125, 2018.

[9] C. Hwang and K. Yoon, Multiple attribute decision making: methods and applications, A State of the Art Survey, Lecture Notes in Economics and Mathematical Systems 186, SpringerVerlag, Berlin, Germany, 1981.

[10] C. L. Hwang, Y. J. Lai, and T. Y. Liu, "A new approach for multiple objective decision making," Computers \& Operations Research, vol. 20, no. 8, pp. 889-899, 1993.

[11] C. N. Liao and H. P. Kao, "An integrated fuzzy TOPSIS and MCGP approach to supplier selection in supply chain management," Expert Systems with Applications, vol. 38, no. 9, pp. 10803-10811, 2011.

[12] G. Torlak, M. Sevkli, M. Sanal, and S. Zaim, "Analyzing business competition by using fuzzy TOPSIS method: an example of Turkish domestic airline industry," Expert Systems with Applications, vol. 38, no. 4, pp. 3396-3406, 2011.

[13] F. Samanlioglu, Y. E. Taskaya, U. C. Gulen, and O. Cokcan, “A fuzzy AHP-TOPSIS-based group decision-making approach to IT personnel selection," International Journal of Fuzzy Systems, vol. 20, no. 5, pp. 1576-1591, 2018.

[14] S. Yousefzadeh, K. Yaghmaeian, A. H. Mahvi, S. Nasseri, N. Alavi, and R. Nabizadeh, "Comparative analysis of hydrometallurgical methods for the recovery of $\mathrm{Cu}$ from circuit boards: optimization using response surface and selection of the best technique by two-step fuzzy AHP-TOPSIS method," Journal of Cleaner Production, vol. 249, Article ID 119401, 2020.

[15] F. Samaie, H. Meyar-Naimi, S. Javadi, and H. Feshki-Farahani, "Comparison of sustainability models in development of electric vehicles in Tehran using fuzzy TOPSIS method," Sustainable Cities and Society, vol. 53, Article ID 101912, 2020.

[16] F. S. Abdulgader, R. Eid, and B. D. Rouyendegh, "Development of decision support model for selecting a maintenance plan using a fuzzy MCDM approach: a theoretical framework," Applied Computational Intelligence and Soft Computing, vol. 2018, Article ID 9346945, 2018.

[17] B. D. Rouyendegh, A. Yildizbasi, and P. Üstünyer, "Intuitionistic Fuzzy TOPSIS method for green supplier selection problem," Soft Computing, vol. 24, pp. 2215-2228, 2020.

[18] D. E. Ighravwe, M. O. Babatunde, I. H. Denwigwe, and D. O. Aikhuele, "A STEEP-cum-SWOT approach for maintenance strategy evaluation for an off-grid PV-powered street lighting system," African Journal of Science, Technology, Innovation and Development, vol. 12, no. 6, pp. 703-714, 2020.

[19] K. Kokkinos and V. Karayannis, "Supportiveness of lowcarbon energy technology policy using fuzzy multicriteria decision-making methodologies," Mathematics, vol. 8, no. 7, 2020.

[20] T. Ali, H. Ma, and A. J. Nahian, "Justification of solar Home system in rural Bangladesh based on risk indicators: an integrated multi-criteria decision making approach," International Journal of Renewable Energy Research, vol. 9, pp. 1948-1956, 2019.

[21] C. Bai, S. Kusi-Sarpong, H. Badri Ahmadi, and J. Sarkis, "Social sustainable supplier evaluation and selection: a group decision-support approach," International Journal of Production Research, vol. 57, no. 22, pp. 7046-7067, 2019.

[22] A. Kumar, A. Aswin, and H. Gupta, "Evaluating green performance of the airports using hybrid BWM and VIKOR methodology," Tourism Management, vol. 76, Article ID 103941, 2020.
[23] S. Rahimi, A. Hafezalkotob, S. M. Monavari, A. Hafezalkotob, and R. Rahimi, "Sustainable landfill site selection for municipal solid waste based on a hybrid decision-making approach: fuzzy group BWM-MULTIMOORA-GIS," Journal of Cleaner Production, vol. 248, Article ID 119186, 2020.

[24] M. Gul and M. F. Ak, "Assessment of occupational risks from human health and environmental perspectives: a new integrated approach and its application using fuzzy BWM and fuzzy MAIRCA," Stochastic Environmental Research and Risk Assessment, vol. 34, pp. 1231-1262, 2020.

[25] F. Ecer and D. Pamucar, "Sustainable supplier selection: a novel integrated fuzzy best worst method (F-BWM) and fuzzy CoCoSo with Bonferroni (CoCoSo'B) multi-criteria model," Journal of Cleaner Production, vol. 266, Article ID 121981, 2020.

[26] M. H. Chang, J. J. H. Liou, and H. W. Lo, "A hybrid MCDM model for evaluating strategic alliance partners in the green biopharmaceutical industry," Sustain, vol. 11, pp. 1-20, 2019.

[27] T. W. Chang, H. W. Lo, K. Y. Chen, and J. J. H. Liou, "A novel FMEA model based on rough BWM and rough TOPSIS-AL for risk assessment," Mathematics, vol. 7, 2019.

[28] Z.-P. Tian, H.-Y. Zhang, J.-Q. Wang, and T.-L. Wang, "Green supplier selection using improved TOPSIS and best-worst method under intuitionistic fuzzy environment," Informatica, vol. 29, no. 4, pp. 773-800, 2018.

[29] P. You, S. Guo, H. Zhao, and H. Zhao, "Operation performance evaluation of power grid enterprise using a hybrid BWM-TOPSIS met," Sustain, vol. 9, pp. 1-15, 2017.

[30] A. Norouzi and H. Ghayur Namin, "A hybrid fuzzy TOPSIS best worst method for risk prioritization in megaprojects," Civil Engineering Journal, vol. 5, no. 6, pp. 1257-1272, 2019.

[31] K. Mathiyazhagan, A. Gnanavelbabu, and B. Lokesh Prabhuraj, "A sustainable assessment model for material selection in construction industries perspective using hybrid MCDM approaches," Journal of Advances in Management Research, vol. 16, no. 2, pp. 234-259, 2019.

[32] M. Yucesan, S. Mete, F. Serin, E. Celik, and M. Gul, "An integrated best-worst and interval type-2 fuzzy TOPSIS methodology for green supplier selection," Mathematics, vol. 7, 2019.

[33] N. K. Ibrahim, N. S. Jalood, M. J. Baqer et al., "Multi-criteria evaluation and Benchmarking for young learners' English language mobile applications in terms of LSRW skills," IEEE Access, vol. 7, pp. 146620-146651, 2019.

[34] J. Gan, S. Zhong, S. Liu, and D. Yang, "Resilient supplier selection based on fuzzy BWM and GMo-RTOPSIS under supply chain environment," Discrete Dynamics in Nature and Society, vol. 2019, Article ID 2456260, 2019.

[35] W. Serrai, A. Abdelli, L. Mokdad, and Y. Hammal, "Towards an efficient and a more accurate web service selection using MCDM methods," Journal of Computational Science, vol. 22, pp. 253-267, 2017.

[36] D. Karabasevic, D. Stanujkic, M. Brazkovic, M. Maksimovic, and P. Brzakovic, "The evaluation of websites in the textile industry by applying ISO/IEC 9126-4 standard and the EDAS method," Industria Textila, vol. 69, no. 6, pp. 489-494, 2018.

[37] E. A. Adali and A. T. U. Ş. Işik, "Ranking web design firms with the ORESTE method," Ege Academic Review, vol. 17, pp. 243-254, 2017.

[38] G. Büyüközkan and S. Güleryüz, "Lojistik firma web sitelerinin performanslarinin çok kriterli degerlendirilmesi," Journal of the Faculty of Engineering and Architecture of Gazi University, vol. 31, pp. 889-902, 2016. 
[39] B. D. Rouyendegh, K. Topuz, A. Dag, and A. Oztekin, "An AHP-IFT integrated model for performance evaluation of E-commerce web sites," Information Systems Frontiers, vol. 21, pp. 1345-1355, 2019.

[40] F. A. Lootsma, Fuzzy Logic for Planning and Decision Making, Applied Optimization, Springer, New York, NY, USA, 1997.

[41] L. A. Zadeh, "Fuzzy logic, neural networks, and soft computing," Communications of the ACM, vol. 37, no. 3, pp. 77-84, 1994.

[42] C.-T. Chen, "Extensions of the TOPSIS for group decisionmaking under fuzzy environment," Fuzzy Sets and Systems, vol. 114, no. 1, pp. 1-9, 2000.

[43] https://www.travelclick.com/, 2020.

[44] http://sosyalkarinca.com/, 2020.

[45] https://www.pompaa.com/, 2020.

[46] https://www.sarvon.com/, 2020. 